\title{
ANÁLISIS DE LA CIRCUNSTANCIA AGRAVANTE DE DISCRIMINACIÓN POR RAZONES DE GÉNERO $\left(22.4^{\mathrm{a}} \mathrm{CP}\right)$
}

\author{
María Jéssica Seoane Marín* \\ Inés Olaizola Nogales**
}

Resumen: El presente trabajo se centra en el estudio de la agravante genérica por "razones de género" (art. 22.4 del CP); circunstancia modificativa incorporada a nuestro Código Penal mediante la LO 1/2015, de 30 de marzo. Se analizan, en primer lugar, las causas que motivan su introducción en nuestra normativa penal, y se efectúa una aproximación al fundamento de la agravante. Posteriormente, se trata la diferencia entre la agravante de sexo y la de género, y se prosigue con el análisis de los preceptos a los que podría ser de aplicación la circunstancia agravante, tomando en consideración para ello el principio de inherencia. Se

Recibido: marzo 2019. Aceptado: junio 2019

* Letrada ejerciente en el Departamento Procesal-Concursal de ARPA A\&C, S.L. Paseo de Pablo Sarasate $n^{\circ} 5,1^{\circ}$ Derecha, CP 31002 Pamplona, Navarra.

E-mail: mjseoane@micap.es

** Catedrática de Derecho Penal. ORCID iD: https://orcid.org/0000-0002-9708644X

Departamento de Derecho de la Facultad de Ciencias Jurídicas de la Universidad Pública de Navarra. Campus de Arrosadía CP 31006 Pamplona, Navarra. E-mail: ines@unavarra.es 
concluye indicando que la agravante de género constituye una aportación novedosa en nuestra normativa, sin que esté destinada a cumplir una mera función simbólica.

Palabras clave: Circunstancias modificativas. Agravantes. Discriminación por género. Razones de género. Violencia de género.

\title{
ANALYSIS OF THE AGGRAVATING CIRCUMSTANCE FOR GENDER REASONS (22.4 CRIMINAL CODE)
}

\begin{abstract}
This article focus on the insertion of aggravating circumstance for gender reasons, mentioned in art. 22.4 of the Criminal Code, through the Organic Law 1/2015 of 30th of March. Firstly, the reasons given by the legislator for incorporating this aggravation are analysed and an approximation to the basis of the aggravating circumstance is made. Furthermore, the difference between the aggravating circumstance for sex reasons and that of gender reasons is discussed, and the precepts to which the aggravating circumstance could be applied are analysed, considering the principle of inherence. It concludes by stating that the gender aggravation constitutes a novel contribution in our regulation, without being destined to meet only a symbolic role.
\end{abstract}

Keywords: Modifying circumstances. Aggravating circumstances. Gender discrimination. Gender reasons. Gender-based violence.

\section{Origen de la circunstancia agravante de discrimi- nación por razones de género}

La Ley Orgánica 1/2015, de 30 de marzo, por la que se modifica la Ley Orgánica 10/1995, de 23 de noviembre, del Código Penal, introduce en el vigente Código una circunstancia agravante "por razones de género"1. Las razones de género se incorporan así al amplio elenco de motivos discriminatorios

1 Código Penal, Artículo 22. 4. ${ }^{\text {a: }}$ Cometer el delito por motivos racistas, antisemitas u otra clase de discriminación referente a la ideología, religión o creencias de la víctima, la etnia, raza o nación a la que pertenezca, su sexo, orientación o identidad sexual, razones de género, la enfermedad que padezca o su discapacidad. 
cuya concurrencia da lugar a la aplicación de esta circunstancia agravante contemplada en el art. $22.4^{\circ} \mathrm{CP}$.

La propia Exposición de Motivos justifica la reforma en la necesidad de "reforzar la protección especial que actualmente dispensa el Código Penal a las víctimas de la violencia de género", así como en la obligación de adecuarse a los compromisos internacionales del Estado español, como el Convenio n. ${ }^{\circ} 210$ del Consejo de Europa sobre prevención y lucha contra la violencia contra las mujeres y la violencia doméstica, aprobado en Estambul por el Comité de Ministros del Consejo de Europa el 7 de abril de 2011 (Convenio de Estambul)2.

Indica asimismo la Exposición de Motivos que la novedad de esta agravante obedece a que el género, entendido como "los papeles, comportamientos o actividades y atribuciones socialmente construidos que una sociedad concreta considera propios de mujeres o de hombres"3, "puede constituir un fundamento de acciones discriminatorias diferente del que abarca la referencia al sexo".

El denominado Convenio de Estambul reconoce en su Preámbulo que la violencia contra la mujer es una manifestación de desequilibrio histórico entre la mujer y el hombre que ha llevado a la dominación y a la discriminación de la mujer por el sujeto varón, privando así a ésta de su plena emancipación. Igualmente, contempla que la naturaleza estructural de la violencia contra la mujer está basada en el género, y que esta forma de violencia constituye uno de los mecanismos sociales cruciales por los que se mantiene a las mujeres en una posición de subordinación con respecto a los hombres, estando éstas y las niñas notablemente más expuestas que los varones a un riesgo elevado de este tipo de violencia.

2 Ratificado por el Estado español el 6 de junio de 2014 y en vigor desde el 1 de agosto de 2014.

3 Definición de Género contemplada en el artículo 3 del Convenio del Consejo de Europa sobre Prevención y Lucha contra la Violencia contra la Mujer y la Violencia Doméstica. Estambul. 11 de mayo de 2011. 
Se trata de un Convenio que supone el primer instrumento de carácter vinculante en el ámbito europeo en materia de violencia contra la mujer y violencia doméstica, siendo asimismo el tratado internacional de mayor alcance para hacer frente a esta grave violación de los derechos humanos, pues efectivamente establece una tolerancia cero con respecto a la violencia hacia la mujer".

Sin perjuicio de que el presente trabajo no trata directamente sobre el concepto de violencia de género, consideramos que la propia agravante, así como el análisis ulterior que se realizará sobre la aplicabilidad de la misma, debe previamente contextualizarse a través de unas breves nociones acerca del concepto de este tipo de violencia, máxime cuando las definiciones internacionales difieren en parte de la aportada a nivel nacional por la Ley Orgánica 1/2004 de Medidas de Protección Integral contra la Violencia de Género.

Precisamente, a nivel internacional el propio Convenio de Estambul establece como punto de partida las siguientes definiciones:

1.- "Por violencia contra la mujer, se deberá entender una violación de los derechos humanos y una forma de discriminación contra las mujeres, y se designarán todos los actos de violencia basados en el género que implican o pueden implicar para las mujeres daños o sufrimientos de naturaleza física, sexual, psicológica o económica, incluidas las amenazas de realizar dichos actos, la coacción o la privación arbitraria de libertad, en la vida pública o privada".

2.- "Por género se entenderán los papeles, comportamientos, actividades y atribuciones socialmente construidos que una sociedad concreta considera propios de mujeres o de hombres."

3.- "Por violencia contra la mujer por razones de género, se entenderá toda violencia contra una mujer porque es una mujer o que afecte a las mujeres de manera desproporcionada" 5 .

4 MUÑOZ COMPANY, Diario La Ley, nº 8606, 2015, p. 3.

5 Convenio del Consejo de Europa sobre Prevención y Lucha contra la Violencia contra la Mujer y la Violencia Doméstica. Estambul. 11 de mayo de 2011. Artículo 3. 
Por su parte, la Declaración de Naciones Unidas ${ }^{6}$ define la violencia contra la mujer como "todo acto de violencia basado en la pertenencia al género femenino que tenga o pueda tener como resultado un daño o sufrimiento físico, sexual o psicológico para las mujeres, inclusive las amenazas de tales actos, la coacción o privación arbitraria de libertad, tanto si se producen en la vida pública como privada".

En sede nacional es el precepto 1 de la Ley Orgánica $1 / 2004$ el que define la violencia de género como una "violencia que, como manifestación de la discriminación, la situación de desigualdad y las relaciones de poder de los hombres sobre las mujeres, se ejerce sobre éstas por parte de quienes sean o hayan sido sus cónyuges o de quienes estén o hayan estado ligados a ellas por relaciones similares de afectividad, aun sin convivencia".

Bajo nuestro punto de vista, de todas las definiciones legales de violencia de género analizadas es esta última la menos acertada y ello porque este tipo de violencia se caracteriza por el sujeto pasivo que la sufre: el blanco de la violencia de género siempre será la mujer por el mero hecho de ser mujer. Y si bien es cierto que será habitual encontrarnos con un sujeto activo varón - manifestación plena de la falta de igualdad entre sexos-, no siempre será así. La explotación sexual femenina, las lapidaciones a mujeres, los matrimonios forzados, las mutilaciones genitales o los abortos selectivos, constituyen sin lugar a dudas manifestaciones claras de violencia de género; y no porque el sujeto activo sea perteneciente a uno $\mathrm{u}$ otro sexo, sino porque la víctima es mujer y la violencia viene motivada por su rol de mujer ${ }^{7}$.

De los ejemplos últimos se desprende el segundo error que comete la definición legal contemplada en la Ley Orgánica

6 Declaración de Naciones Unidas para la eliminación de la violencia contra las mujeres. Resolución 48/104 de la Asamblea General de 20 de diciembre de 1993.

7 LAURENZO COPELLO en LAURENZO/MAQUEDA/RUBIO (coords)., Género, violencia y derecho, 2008, pp. 346 y ss. 
de Violencia de Género: restringir exclusivamente el concepto de la violencia contra la mujer al ámbito de las relaciones de pareja. Como expone LARRAURI PIJOAN, esta forma de definir la violencia de género ha supuesto que los ataques contra la mujer pareja sean castigados con una pena superior a los realizados contra otras mujeres pertenecientes al núcleo familiar - hijas, madres o hermanas-, ha provocado que los Juzgados de Violencia sobre la Mujer conozcan sólo de aquellos casos en los que la víctima es la mujer pareja - a salvo de la excepción contemplada en el artículo 44.1 LOVG-y, por último, ha generado que los recursos asistenciales específicos previstos en una Ley Integral como es la de Violencia de Género se limiten exclusivamente a las mujeres pareja ${ }^{8}$.

No nos encontramos ante una forma de violencia individual que se ejerce en el ámbito familiar o de pareja por quien ostenta una posición de superioridad física (hombre) sobre el sexo más débil (mujer), pues ello supondría simplificar en exceso la realidad que se esconde tras la llamada "violencia de género". Debemos partir de que este tipo de violencia es consecuencia de una situación de discriminación intemporal que tiene su origen en una estructura social de naturaleza patriarcal ${ }^{9}$. El género se constituye así en el resultado de un proceso de construcción social mediante el que se adjudican simbólicamente las expectativas y valores que cada cultura atribuye a sus varones y mujeres ${ }^{10}$. A consecuencia de esa evolución social se procede a asignar bajo la etiqueta de género un conjunto de roles o identidades que adquieren, de forma general, un matiz subordinado en el caso de las mujeres.

En resumen, bajo esta premisa de subordinación y discriminación se entiende una clase de violencia que afecta a las mujeres por el hecho mismo de ser mujeres, pero no por el con-

8 LARRAURI PIJOAN, Criminología crítica y violencia de género, 2007, p. 48.

9 MAQUEDA ABREU, Revista Electrónica de Ciencia Penal y Criminología, $\mathrm{n}^{\circ} 8,2006$, p. 2.

10 BERGALLI/BODELÓN GONZÁLEZ, Anuario de Filosofia del Derecho IX. 1992, p. 53. 
junto de rasgos biológicos que diferencian a las mismas del sexo opuesto - esa superioridad física a la que hacíamos referencia-, sino por unos roles específicos atribuidos a lo femenino cuyo origen es social, estructural y cultural ${ }^{11}$.

\section{Fundamento de la circunstancia agravante de discrimi- nación por razones de género}

Bien es sabido que la prohibición de no discriminar tiene su origen en sede constitucional y, en particular, en el derecho a la igualdad y a la prohibición de discriminación consagrado en el artículo 14 de la Constitución Española (CE). A este precepto necesariamente ha de acompañarle el artículo 9.2 CE, que ordena a los poderes públicos la promoción de la igualdad real y efectiva de individuos y grupos, el precepto 32.1 CE que consagra la plena igualdad jurídica entre hombres y mujeres por razón del matrimonio, o el artículo 35.1 CE cuando prohíbe la discriminación por razón de sexo respecto al derecho del trabajo, a la libre elección de profesión y oficio.

Centrándonos en el artículo 14 de la $\mathrm{CE}$, el mismo contiene dos disposiciones: en primer lugar, la positivización del principio de igualdad y, en segundo lugar, la prohibición de discriminación por razón de nacimiento, raza, sexo, religión, opinión o cualquier otra condición o circunstancia personal o social. Como se puede observar, respecto al segundo mandato se recogen diversas razones a título meramente enunciativo; esto es, en ningún caso nos encontramos ante un elenco cerrado de supuestos objeto de discriminación, sino que el legislador al elaborar la Carta Magna extiende esa interdicción discriminatoria "a cualquier otra condición o circunstancia personal o social". Es precisamente esta prohibición de discriminación la que se traslada al Código Penal a través de, entre otros preceptos ${ }^{12}$, la

11 LAURENZO COPELLO en LAURENZO/MAQUEDA/RUBIO (coords.), Género, violencia y derecho, 2008, pp. 344-345.

12 Obsérvese el artículo 314 CP (prohibición de discriminación en el ámbito laboral), el precepto $510 \mathrm{CP}$ (provocación a la discriminación), los artículos 
agravante genérica de discriminación regulada en el artículo $22.4 \mathrm{CP}^{13}$.

A este respecto, LAURENZO COPELLO afirma que el trato discriminatorio podría catalogarse como aquel comportamiento que conlleva implícitamente una negación de igualdad entre los seres humanos, negación fundamentada en ciertos rasgos o peculiaridades que distinguen al discriminado del modelo de normalidad que se toma como punto de referencia ${ }^{14}$.

A nivel jurisprudencial, resulta de utilidad el análisis de la Sentencia de la Audiencia Provincial de Madrid n ${ }^{\circ}$ 717/2010, de 28 de junio, cuando, al tratar un supuesto de discriminación por motivos racistas, sintetiza diversa jurisprudencia emanada del Tribunal Supremo, así como de otras Audiencias Provinciales, para llegar a definir los criterios que caracterizan a esta agravante genérica por motivos discriminatorios contenida en el $22.4 \mathrm{CP}$ :

"La jurisprudencia que se ha elaborado en torno a esta circunstancia agravante, reciente, puesto que se estableció por primera vez en 1994, se ha centrado en exigir que para que la misma concurra en cualquier supuesto delictivo es preciso que figuren acreditados hechos que demuestren que la motivación que ha llevado al agresor a su realización ha tenido como causa la de la discriminación.

Esto implica — continúa la Sentencia- que, bajo nuestro criterio, los elementos que definen a esta circunstancia agravante son:

$\left.1^{\circ}\right)$ Que haya quedado claramente acreditado que la persona agredida forma parte de un grupo, o de un colectivo que podemos calificar como minoritario, no coincidente con la ma-

511 y 512 CP (denegación de prestaciones correspondientes a un servicio público o privado) o el $515.5^{\circ} \mathrm{CP}$ (denegación de prestaciones correspondientes a un servicio público o privado).

13 ReBOLlO VARGAS, Revista General de Derecho Penal, nº 23, 2015, p. 3.

14 LAURENZO COPELlO, Estudios Penales y Criminológicos, vol. XIX, 1996, pp. 235-236. 
yoría social y, por lo menos en parte, rechazado por ésta y que objetivamente puede ser objeto de discriminación.

$2^{\circ}$ ) Que se acredite objetivamente que en el hecho ilícito que se juzga existan elementos que exterioricen el desprecio por la minoría afectada.

$3^{\circ}$ ) Que en el hecho ilícito al que se aplica la agravante no aparezcan otras justificaciones que pudieran explicar por sí mismas la motivación de la actividad ilícita, o que, apareciendo, no sean determinantes precisamente del acto ilícito"15.

Efectivamente, en cuanto a este último punto ya se había pronunciado claramente la Sentencia de la Audiencia Provincial de Cuenca ${ }^{\circ}$ 49/1998, de 7 de julio, al determinar que resultaba de aplicación la agravante de discriminación contenida en el $22.4 \mathrm{CP}$ siempre que el motivo discriminatorio fuera el preponderante:

"Así, la mayor parte de los autores han llegado a entender, incluso, que la circunstancia puede apreciarse cuando la intención discriminatoria concurre con otras, pero siempre que aquélla sea la motivación consciente más próxima $o$, si se quiere, predominante. Igualmente, ha llegado a proponerse, como una suerte de teoría de equivalencia de las motivaciones que el aplicador del Derecho deberá preguntarse, a la hora de valorar la posible aplicación de esta circunstancia, si prescindiendo del móvil discriminatorio (eventualmente existente) el delito se habría cometido igualmente o si, por el contrario, sin aquél no habría tenido lugar éste, apreciando la circunstancia en el primer caso y despreciándola en el segundo [...]"16.

Con carácter general los tribunales vienen exigiendo, para la aplicación de cualquiera de los motivos contenidos en el precepto $22.4 \mathrm{CP}$, la ejecución de un acto delictivo en base a móviles que encuentran su fundamento preponderante en la discriminación - hacia el colectivo femenino, en nuestro caso-. Por

15 Sentencia de la Audiencia Provincial de Madrid n ${ }^{\circ} 717 / 2010$, de 28 de junio. 16 Sentencia de la Audiencia Provincial de Cuenca no 49/1998, de 7 de julio. 
nuestra parte, y como más adelante concluiremos, consideramos que no será necesaria la acreditación de ese móvil subjetivo discriminatorio, sino que será suficiente con demostrar que de la conducta del autor se deriva un efecto objetivamente discriminatorio sobre la víctima ${ }^{17}$.

El Tribunal Supremo considera que, para determinar si se produce o no ese efecto discriminatorio sobre la víctima, ha de quedar patente, en primer lugar, cuál es la motivación fundamental del autor al cometer el delito; qué razón principal es la que preside el comportamiento del sujeto activo y, efectivamente, le impulsa a perpetrar el crimen. La jurisprudencia defiende que se trata de analizar la concurrencia en la mente del autor de un concreto proceso psíquico interno que es el que determina la comisión de delito, siendo este móvil indeseable o especial ánimo subjetivo el que se traduce en un incremento de su culpabilidad que, posteriormente, justifica la imposición de una mayor penalidad. O como diría la Sentencia de Tribunal Supremo ${ }^{\circ}$ $1145 / 2006$, de 23 de noviembre, al respecto de la agravante de discriminación por razón de sexo: "Se trata de una circunstancia que se fundamenta en la mayor culpabilidad del autor por la mayor reprochabilidad del móvil que impulsa a cometer el delito, siendo por ello requisito que aquella motivación sea la determinante para cometer el delito".

Precisamente, el Alto Tribunal en su Sentencia $\mathrm{n}^{\circ}$ $420 / 2018$, de 25 de septiembre, ha definido ese elemento subjetivo al que hacíamos referencia como una "intención de dominación del hombre sobre la mujer, que dentro de las relaciones de pareja es considerada por el autor como un ser inferior, vulnerando, por lo tanto, su derecho a la igualdad". En el mismo sentido, su Sentencia ${ }^{\circ} 565 / 2018$, de 19 de noviembre, confirma que la agravante por razones de género posee un fundamento subjetivo "necesitando que concurra en el autor del delito un ánimo de mostrar su superioridad frente a la víctima mujer y

17 En el mismo sentido, vid. Sentencia de la Audiencia Provincial de Barcelona $\mathrm{n}^{\circ} 32 / 2003$, de 26 de octubre. 
demostrarle que ésta es inferior por el mero hecho de serlo. Es evidente que el fundamento de las agravaciones recogidas en este apartado $4^{\circ}$ reside en el mayor reproche penal que supone que el autor cometa los hechos motivado por sentirse superior a uno de los colectivos que en el mismo se citan y como medio para demostrar además a la víctima que la considera inferior".

Entre la doctrina existe una constatada discusión acerca de si el fundamento de las circunstancias agravantes contenidas en el artículo 22.4 CP debe obedecer a un incremento del injusto del hecho o si, por el contrario, debe elevar el reproche de la culpabilidad. Al respecto de esto último, ALONSO ÁLAMO - entre otros defensores de esta tendencia doctrinal que resulta mayoritaria entre la jurisprudencia - trata de expresar la relevancia de la motivación discriminatoria contenida en el precepto 22.4 CP para el juicio de culpabilidad, tanto en lo concerniente "al proceso de motivación, pero también a la actitud interna, a la disposición moral, a las tendencias e impulsos y, en definitiva, a la personalidad total del autor reflejada en el hecho"18. Debemos adelantar que no podemos decantarnos por esta última opción y ello porque, al margen de los inconvenientes probatorios que luego expondremos, el hecho de hacer depender el fundamento de la agravante de elementos tan próximos al carácter y forma de ser del autor nos podría abocar al Derecho penal de autor ${ }^{19}$. Tampoco es posible esgrimir en defensa de esta postura el hecho de que tomamos en consideración las motivaciones últimas del sujeto, no como un rasgo permanente de su personalidad, sino únicamente de forma puntual cuando esta manifestación de su carácter se materializa en una conducta delictiva. Como expone DOPICO GÓMEZ-ALLER, resulta ilegítimo el acceso al fuero interno del sujeto -incluso aunque sólo analicemos el de los sujetos activos infractores- pues, si nuestra Constitución

18 ALONSO ÁLAMO, La circunstancia agravante de discriminación, 2002, p. 541.

19 Sentencia del Tribunal Constitucional, no 150/1991: "no sería constitucionalmente legítimo un derecho penal 'de autor' que determinara las penas en atención a la personalidad del reo". 
no permite castigar la ideología de ningún sujeto, tampoco su ideología al cometer una infracción ${ }^{20}$, al margen de que ésta nos parezca sumamente indeseada o despreciable desde el punto de vista moral.

En un reciente trabajo, RUEDA MARTÍN defiende la exigencia del móvil discriminatorio para la posible aplicación de esta agravante, entendiendo que dicha exigencia no tiene por qué suponer una manifestación del Derecho penal de autor. Afirma la autora que atender a determinados móviles, motivos o actitudes internas del sujeto activo no debe conducir necesariamente a interpretar los tipos conforme al Derecho penal de autor, porque sólo se desvaloran de manera jurídico-penalmente relevante si se evidencian en el curso de un comportamiento concreto que reviste determinados caracteres. Por el contrario, continúa RUEDA MARTÍN: "dicha exigencia es compatible con un Derecho penal del hecho, porque se castigan hechos concretos realizados por un autor que ha actuado de un determinado modo dada la condición de la víctima, y ello fundamenta tanto una mayor gravedad de lo injusto por el abuso de la posición de dominio que ostenta el agresor, como de la culpabilidad por concurrir un móvil discriminatorio hacia la mujer por razón de su sexo a la que se le atribuye un rol sexual y una inferioridad en cualquier ámbito, incluidas las agresiones de un hombre hacia una mujer en su relación de pareja" ${ }^{21}$. Entendemos que, si bien esta autora considera necesario el móvil discriminatorio, es importante tener en cuenta que cuando lo define lo hace como aquella situación de dominio en el que el sujeto atribuye a la víctima un rol sexual y una condición de inferioridad que, según esta autora, podrán acreditarse mediante la prueba de determinados comportamientos llevados a cabo por el autor. Por lo tanto, RUEDA MARTÍN, aunque acepta la exigencia del móvil discriminatorio, se conforma para su prueba con la realización de comportamientos externos del autor.

20 DOPICO GÓMEZ-ALLER, ADPCP, vol. LVII, 2004, p. 153.

21 RUEDA MARTÍN, RCPC 21-04 (2019), p. 28. 
En nuestra opinión, no consideramos lo más acertado hacer depender la aplicación de la agravante de un elemento puramente subjetivo, con las dificultades probatorias que implícitamente ello conlleva pues, como expone LARRAURI PIJOAN al tratar las figuras de género específicas, la necesidad de acreditar un elemento subjetivo de humillación o discriminación hacia la mujer conlleva en muchas ocasiones la inaplicación de los tipos penales así concebidos. De este modo, si la finalidad de humillar o discriminar se interpreta de forma muy amplia, todos los delitos contra las mujeres pueden entenderse cometidos por razones de su género o con el fin de dominarlas. Por el contrario, si se exige que se demuestre que ésta es la única finalidad o la prioritaria, ello puede llevar a la inaplicación absoluta de las figuras delictivas $^{22}$. Por otro lado, hacer depender la aplicabilidad de la agravante solamente de la motivación del autor traería como consecuencia un problema fundamental como es la imposibilidad de distinguir entre motivaciones conscientes e inconscientes, amén de que la gravedad del delito no puede determinarse simplemente atendiendo a la gravedad de la culpabilidad que atribuyamos al autor en función de su motivación, sino que la gravedad del delito dependerá además de la gravedad de la lesión generada al bien jurídico de que se trate ${ }^{23}$.

Coincidimos con autores como MIR PUIG al entender que todas las circunstancias agravantes deben aumentar lo injusto penal del hecho, sin que puedan elevar la imputación personal del autor. No se trata de analizar la parte subjetiva del hecho ni tampoco la actitud interna del sujeto, sino sólo los elementos - objetivos a nuestro juicio- que condicionan la atribución del injusto penal a su autor ${ }^{24}$. Asimismo, en cuanto a la posible "elevación" de la imputación personal del sujeto activo resulta sumamente interesante el planteamiento que efectúa DOPICO

22 LARRAURI PIJOAN, Criminología crítica y violencia de género, 2007, p. 129.

23 DÍAZ LÓPEZ, El odio discriminatorio como agravante penal: sentido y alcance del artículo 22.4. ${ }^{a} \mathrm{CP}, 2013$, p. 348.

24 MIR PUIG, Derecho Penal. Parte General, 2016, pp. 648-649. 
GÓMEZ-ALLER al cuestionarse cómo es posible que un hecho delictivo cometido sin motivación discriminatoria alguna pueda ser entendido como plenamente imputable al autor y admitir al mismo tiempo que, de haber concurrido la circunstancia agravante del artículo indicado, se le hubiera atribuido una imputación mayor ${ }^{25}$. En otras palabras, el sujeto automáticamente ya es culpable en su totalidad al cometer el delito que nos ocupa, sin que sea posible atribuirle mayor culpabilidad; cuestión distinta es que se pueda incrementar el desvalor de su conducta atribuyéndole un mayor injusto.

Lo siguiente que habremos de plantearnos es cómo fundamentamos exactamente ese mayor injusto para que traiga como resultado irremediable la aplicación de la agravante. Precisamente, fue LAURENZO COPELLO quien prematuramente ya estableció ese plus de agravación de los delitos cometidos por motivos discriminatorios en el desvalor adicional del injusto que conforma la lesión del otro bien jurídico penal lesionado: el derecho del sujeto pasivo a no ser discriminado, esto es, "a ser tratado como un ser humano igual a cualquier otro"26.

Coincidimos con diversos autores ${ }^{27}$ que defienden la sustitución de este elemento subjetivo por un contexto objetivo de dominación que se pueda determinar mediante un conjunto de hechos externos. Como acertadamente expone LAURENZO COPELLO, es ampliamente conocido que el concepto de violencia de género hace referencia a relaciones de poder, pero carece de sentido deducir que cada golpe, cada amenaza o cada coacción deben por ello realizarse con un ánimo específico de dominar a la mujer en esa situación. Y prosigue la autora explicando que lo determinante no serán los motivos o razones que llevan al autor a ejercer la violencia en ese momento o situación

25 DOPICO GÓMEZ-ALLER, ADPCP, vol. LVII, 2004, p. 153.

26 LAURENZO COPELlO, Estudios Penales y Criminológicos, vol. XIX, 1996, p. 281.

27 Entre otros, vid. LARRAURI PIJOAN, Criminología crítica y violencia de género, 2007, pp. 124 y ss. LAURENZO COPELLO, Estudios Penales y Criminológicos, Vol. XXXV, 2015, pp. 819 y ss. 
concreta, sino el hecho en sí de utilizarla como forma de relacionarse con su pareja, desarrollando una pauta de conducta que efectivamente tiene que ver con las relaciones de dominio y subordinación entre los sexos propias del patriarcado. De hecho, sin perjuicio de la exigencia por parte del Alto Tribunal del elemento subjetivo antes referido, la idea que pretendemos transmitir podría quedar reflejada en su Sentencia no 565/2018, de 19 de noviembre, cuando indica que "aparecen conectados todos los hechos declarados probados en ese ambiente de dominación y machismo del acusado que conforma todos los actos delictivos bajo la estigmatización que provoca en los sentimientos de la víctima y que se desarrolla en la ejecución de actos tendentes a conseguir la posesión física e intelectual por el sujeto autor del delito hacia la víctima y doblegar su voluntad para quedar sometida".

Resulta indudable asimismo que el sujeto en cuestión ha de formar parte de uno de los colectivos históricamente discriminados que se sitúan, con motivo de sus señas de identidad, en una posición inferior y marginada desde el punto de vista social — "modelo de la selección discriminatoria" o discriminatory selection model ${ }^{28}$ —. Únicamente en esta razón radica la explicación de que el sujeto activo escoja a esa víctima concreta en lugar de a cualquier otra que no forma parte del grupo discriminado $^{29}$.

Es interesante la propuesta esgrimida por LANDA GOROSTIZA quien, partiendo de la idea inicial de LAURENZO COPELLO, también fundamenta el carácter objetivo de la agravación en la concurrencia de un desvalor adicional del injusto, pero, en este caso, dotándolo de un contenido supraindividual que va más allá de la lesión producida al sujeto particular objeto de lesión. Este plus de antijuridicidad de la conducta vendría ca-

28 LANDA GOROSTIZA, InDret, 3/2014, p.14.

29 MAQUEDA ABREU en SILVA/QUERALT/CORCOY/CASTIÑEIRA (coords.), Estudios de Derecho Penal: homenaje al profesor Santiago Mir Puig, 2017, pp. 711 y ss. 
racterizado por su idoneidad para "conmocionar las condiciones de seguridad existencial del colectivo especialmente vulnerable al que pertenece el sujeto contra el que se ha cometido el delito común precisamente por razones de raza, etnia, ideología, orientación sexual..." 30 . Añade el autor que se "produce una escalada de gravedad que convierte la conducta en idónea para transmitir un mensaje amenazante, para conmover las condiciones de seguridad existencial del colectivo especialmente vulnerable"31. Ahondando en esta misma hipótesis DOPICO GÓMEZALLER $^{32}$ defiende que este "efecto comunicativo amenazante" sería similar al que transmiten a la sociedad los atentados terroristas, esto es, el autor al cometer el delito infringe, no sólo la norma concreta contenida en el precepto penal de que se trate, sino también lo que JAKOBS denominaría "una norma de flanqueo": una norma que protege la seguridad de ciertas personas que pertenecen a determinados grupos caracterizados por una raza, una orientación sexual, etc. y que podría traducirse en una expectativa de indemnidad de todos ellos ${ }^{33}$.

Ahora bien, en relación al quebranto de este bien jurídico supraindividual, no somos ajenas a las consideraciones que el propio LANDA GOROSTIZA pone de manifiesto y que se devengarían de la incerteza respecto a la repercusión que pudiera verificarse en el colectivo del que forma parte la víctima de la agresión, o de los considerables problemas probatorios referentes a la quiebra del sentimiento de tranquilidad del colectivo

30 LANDA GOROSTIZA, La política criminal contra la xenofobia y las tendencias expansionistas del derecho penal, 2001, p. 188.

31 LANDA GOROSTIZA, La política criminal contra la xenofobia y las tendencias expansionistas del derecho penal, 2001, p. 185. Crítico con esta idea se muestra REBOLLO VARGAS, Revista General de Derecho Penal, $\mathrm{n}^{\circ} 23,2015$, p. 22. Para este autor esta visión supraindividual para fundamentar la agravante supondría un discutible adelantamiento de las barreras de punición, pues el objeto de sanción sería la mera perturbación del sentimiento de tranquilidad.

32 DOPICO GÓMEZ-ALLER, ADPCP, vol. LVII, 2004, pp. 166 y ss.

33 JAKOBS, Criminalización en el estadio previo a la lesión de un bien jurídico, 1997, pp. 314 y ss. 
lesionado como consecuencia de la agresión a uno de sus miembros $^{34}$. Por ello, en nuestra opinión, este efecto amenazante para el colectivo podrá considerarse como refuerzo a la hora de afirmar si se da o no una situación de discriminación, pero no será el fundamento de la circunstancia agravante, ni será necesario que se produzca para poder aplicarla.

Hasta aquí podemos concluir una primera idea respecto al fundamento de la agravante por razones de género y es que será necesario acreditar que la conducta delictiva genera en la víctima mujer un resultado indudablemente discriminatorio que la posiciona, de forma objetiva, en un rango inferior. Asimismo, esta acción por parte del autor podrá, en algunas ocasiones, no sólo quebrantar de forma directa la seguridad de la víctima, sino que también de modo indirecto vulnerará las expectativas de protección del resto del colectivo potencialmente discriminado.

Llegados a este punto no podemos sino concluir que la motivación subjetiva del autor ha de quedar relegada a un segundo plano, siendo lo relevante la peligrosidad objetiva que su conducta pueda generar. No será necesario acreditar los motivos, las razones o los móviles — véase la disparidad de términos que son susceptibles de emplearse, cada uno con sus diferentes matices semánticos, cuando nos embarcamos en el terreno subjetivo - que conducen al autor a cometer el delito, ni mucho menos cuál de ellos se antoja el preponderante, o si toma forma consciente o inconsciente en la mente del sujeto activo. Como defiende DOPICO GÓMEZ-ALLER al tratar la agravante genérica de discriminación, "si la explicación dogmática de una institución jurídica basase en elementos de imposible prueba en un proceso, necesariamente estará fallando ya la explicación dogmática, ya la institución en cuestión" ${ }^{35}$.

Como solución a estas dificultades subjetivas, habremos de reinterpretar la literalidad del término "motivos" contenido

34 LANDA GOROSTIZA, La política criminal contra la xenofobia y las tendencias expansionistas del derecho penal, 2001, p. 186.

35 DOPICO GÓMEZ-ALLER, ADPCP, vol. LVII, 2004, p. 170. 
en el artículo $22.4 \mathrm{CP}$ para concederle un significado que haga referencia al "dolo": la consciencia por parte del autor respecto a los elementos constitutivos del delito del que se trate. Ahora bien, el dolo adquirirá en nuestro plano interpretativo la siguiente vertiente: el sujeto activo ha de ser plenamente consciente de estar atacando, con su conducta subsumida en un tipo penal, a un miembro perteneciente a un colectivo ya amenazado - aunque propiamente no se encuentre en una situación crítica- como es el de la población femenina en el caso de la agravante de género $^{36}$.

Con carácter previo a finalizar este apartado es importante resaltar algunas resoluciones del Tribunal Supremo que, diferenciándose de la línea jurisprudencial mayoritaria, apuestan por profundizar en el contexto objetivo. Debemos traer a colación el Auto del Alto Tribunal, de 31 de julio de 2013, donde también propone obviar "un dolo específico de dominio o subyugación de la mujer" indicando que "el contexto comporta ese componente; más allá de las intencionalidades concretas o de la personalidad del autor, o de la forma en que se desencadena el episodio concreto. No hace falta un móvil específico de subyugación, o de dominación masculina. Basta constatar la vinculación del comportamiento, del modo concreto de actuar, con esos añejos y superados patrones culturales, aunque el autor no los comparta explícitamente, aunque no sea totalmente consciente de ello o aunque su comportamiento general con su cónyuge, o ex cónyuge o mujer con la que está o ha estado vinculado afectivamente, esté regido por unos parámetros correctos de trato de igual a igual. Si en el supuesto concreto se aprecia esa conexión con los denostados cánones de asimetría la agravación estará legal y constitucionalmente justificada".

36 DOPICO GÓMEZ-ALLER, $A D P C P$, vol. LVII, 2004, pp. 170 y ss. En el mismo sentido, vid. LANDA GOROSTIZA, Los delitos de odio, 2018, p. 124. Este autor entiende que el sujeto también debe ser consciente de que su mensaje puede ser interpretado, tanto por el colectivo discriminado como por la sociedad en su conjunto, como una advertencia, esto es, el "efecto comunicativo amenazante" que expresábamos en líneas precedentes. 
Asimismo, resulta sumamente interesante a la hora de objetivar la aplicación de la agravante de género la Sentencia $\mathrm{n}^{\circ}$ $856 / 2014$, de 26 de diciembre, del mismo tribunal, que establece la posibilidad de que la presunción actúe en sentido contrario: "Sólo si consta o hay evidencias de que el episodio, concreto o reiterado, de violencia es totalmente ajeno a esa concepción que ha estado socialmente arraigada, y que la agresión o lesión obedece a unas coordenadas radicalmente diferentes, habrá que castigar la conducta a través de los tipos subsidiarios en que la condición de mujer del sujeto pasivo no representa un título de agravación penológica. Pero en principio una agresión en ese marco contextual per se y sin necesidad de prueba especial está vinculada con la concepción que el legislador penal se propone erradicar o al menos reprobar".

Tampoco podemos obviar en este análisis jurisprudencial una de las últimas sentencias dictadas: la STS 99/2019, de 26 de febrero. Resulta relevante a nuestros efectos pues relativiza esa referencia subjetiva al concreto propósito del autor, confirmando que para estimarse aplicable la agravante genérica bastará, por un lado, que "el hecho probado de cuenta de la relación típica prevista en los tipos penales [...] de tal suerte que el delito se entienda como manifestación objetiva de la discriminación característica de la misma" y, por otro lado, en lo subjetivo, defiende que bastará la consciencia de tal relación unida a la voluntad de cometer el delito de que se trate - en otras palabras, ese dolo que exponíamos al tratar el fundamento de la agravante- ${ }^{37}$.

37 Crítica con esta Sentencia se muestra RUEDA MARTÍN, RECPC 21-04 (2019), p. 22. Opina esta autora que si el TS para aplicar la circunstancia agravante del artículo $22.4^{\circ}$ del Código penal, con carácter general, exige demostrar caso por caso que «la motivación racista o discriminatoria haya sido el móvil principal del delito que pretende agravarse», y que «aquella motivación sea la determinante para cometer el delito», no resulta coherente que prescinda de este requisito en la aplicación del concreto apartado referido a la discriminación por razones de género. En segundo lugar, ya se ha explicado que el reconocimiento de que existen diversas clases de violencia en las relaciones de pareja o ex pareja, nos obliga a constatar, mediante la prueba pertinente, cuál es la que concurre en el caso concreto para poder apreciar la agravación de discriminación por razones de género. 
La misma resolución alcanza una lógica conclusión tras remitirse a la Sentencia de Tribunal Supremo n ${ }^{\circ} 677 / 2018$, de 20 de diciembre, la cual no exige un ánimo subjetivo para la aplicación del precepto 153.1 CP, y es que si la exclusión de exigencia de un añadido elemento subjetivo, "como propósito determinante del comportamiento delictivo respecto del que se pretende aplicar la específica agravante, no impide sancionar más gravemente un resultado de menor entidad, conduciéndolo a otro tipo penal más gravoso, sería incoherente reclamar tal componente subjetivo en el actuar injusto para simplemente agravar la pena pero sin salir de la prevista para el tipo penal en el que se discute la aplicación de la agravante como genérica”. Efectivamente, recordemos que, con la aplicación de la agravante contenida en el artículo $22.4 \mathrm{CP}$, nos moveremos dentro de un rango penal ya tipificado por el legislador para el delito de que se trate, pero en ningún caso "convertiremos" el tipo en otro con una pena más gravosa, como sí sucede con las figuras de género específicas.

\section{Diferenciación entre la circunstancia agravante de dis- criminación por razones de género y la de sexo}

Como dejábamos expuesto al comienzo de este trabajo, la Exposición de Motivos de la Ley Orgánica 1/2015 justificaba la incorporación del género como motivo de discriminación en la agravante $4^{\mathrm{a}}$ del artículo 22 del CP indicando que éste podría constituir un fundamento de acciones discriminatorias diferente del que abarcaba la referencia al sexo.

No obstante lo anterior, parte de la doctrina se ha cuestionado si realmente nos encontramos ante una incorporación novedosa en materia de género o si, por el contrario, la misma se trata de un instrumento meramente simbólico que tiene como objetivo cumplir con ciertos compromisos internacionales como los derivados del Convenio de Estambul. En este sentido, AGUILAR CÁRCELES se plantea si dicha iniciativa "responde más a un tipo de Derecho Penal simbólico, que verdaderamente a una necesidad real, pues dichas conductas ya venían siendo 
tipificadas con anterioridad a la reforma" ${ }^{38}$. También BORJA JIMENEZ otorga una función puramente simbólica a la agravante al afirmar que la misma "no va a ampliar la protección de los derechos de la mujer frente a la criminalidad machista, pues los mismos supuestos agravados que puedan considerarse con la nueva ley, tenían de igual forma cobertura con la antigua". Asimismo, señala el autor que, ante la existencia previa de una agravante de sexo, una de identidad sexual, e incluso la circunstancia mixta de parentesco, "no se entiende muy bien, entonces, que, a todo este arsenal punitivo de específica protección de la mujer frente a las más graves conductas machistas, se añada ahora esta modalidad de incremento punitivo por razones de género"39.

En contra, sin embargo, se manifiesta DÍAZ LÓPEZ, quien afirma, refiriéndose a la agravante por razón de sexo, que ésta se aplicará a supuestos de delitos misóginos o de aquellos motivados por el odio al sexo masculino. En el concepto de sexo de la mujer entrarían, además del hecho de tener unos concretos atributos sexuales, aquellas cuestiones vinculadas con los mismos que determinan esta cuestión personal. Así, por ejemplo, el embarazo. De manera, continúa DÍAZ LÓPEZ, que el hecho de que el autor cometa el delito contra una mujer embarazada, porque odia a las mujeres embarazadas, podría dar lugar a la aplicación de la agravante por razón de sexo $^{40}$. Sin embargo, en

38 AGUILAR CÁRCELES en MORILLAS CUEVA (dir.), Estudios sobre el Código Penal reformado, 2015, pp. 58-63.

39 BORJA JIMENEZ en GONZÁLEZ CUSSAC (dir.), Comentarios a la Reforma del Código Penal 2015, 2015, pp. 119-123.

40 DÍAZ LÓPEZ, El odio discriminatorio como agravante penal: sentido y alcance del artículo 22.4. ${ }^{a} \mathrm{CP}, 2013$, pp. 298 y ss. En el mismo sentido la Sentencia del Tribunal Constitucional, n. ${ }^{\circ} 182 / 2005$, de 4 de julio que indica que: "Tal tipo de discriminación comprende, sin duda, aquellos tratamientos peyorativos que se fundan no sólo en la pura y simple constatación del sexo de la víctima, sino en la concurrencia de razones o circunstancias que tengan con el sexo de la persona una conexión directa e inequívoca, como sucede con el embarazo, elemento o factor diferencial que, por razones obvias, incide de forma exclusiva sobre las mujeres (SSTC 173/1994, de 7 de junio, F. 2; 136/1996, de 23 de julio, F. 5; 20/2001, de 29 de enero, F. 4; 41/2002, de 25 de febrero, F. 3; o 17/2003, de 30 de enero, F. 3)". 
opinión de este autor la agravante por razón de sexo no incluye ninguna referencia al género, rol que no tiene nada que ver con el sexo biológico ya que el género encuentra su base en aquellos aspectos socioculturales que estructuralmente asignan determinados roles a lo femenino (género). De esta forma, al igual que en la alusión al género que efectúa la LO 1/2004 no puede verse contenida la noción de sexo, en sentido contrario tampoco puede verse subsumida dentro de la de sexo la noción de género ${ }^{41}$.

Por su parte, en cuanto a la diferenciación entre ambas agravantes, es conocida la doctrina sentada por el Tribunal Constitucional y expuesta, entre otras, en la Sentencia del Pleno, $n^{0}$ 59/2008, de 14 de mayo, la cual dice así: "Como el término 'género' que titula la Ley y que se utiliza en su articulado pretende comunicar, no se trata una discriminación por razón de sexo. No es el sexo en sí de los sujetos activo y pasivo lo que el legislador toma en consideración con efectos agravatorios, sino - una vez más importa resaltarlo- el carácter especialmente lesivo de ciertos hechos a partir del ámbito relacional en el que se producen y del significado objetivo que adquieren como manifestación de una grave y arraigada desigualdad. La sanción no se impone por razón del sexo del sujeto activo ni de la víctima ni por razones vinculadas a su propia biología".

Se debe insistir en que, desde el punto de vista jurisprudencial, el fundamento de la discriminación por razón de género no radica en que el autor actúe con una determinada motivación discriminatoria por razón del sexo de la víctima, sino en que se haya acreditado previamente a la comisión del delito un elemento subjetivo de dominación por razón de género. Dicho de otro modo, se diferencia un delito fundamentado en motivaciones misóginas y otro cometido por razones machistas. En este sentido, es interesante el ejemplo que señala DÍAZ LÓPEZ, refiriéndose al delito de acoso: "es posible que un sujeto machista acose sexualmente a una mujer. Sin embargo, un sujeto que odia

41 DÍAZ LÓPEZ, El odio discriminatorio como agravante penal: sentido y alcance del artículo 22.4. ${ }^{a}$ CP, 2013, pp. 299 y ss. 
a las mujeres no querrá mantener relaciones sexuales con ellas, el sujeto misógino puede acosarlas, pero no lo hará sexualmente, sino por razón de sexo"42.

A raíz de lo expuesto, se podría observar la existencia de una distinción entre las víctimas de la agravante por razón de sexo y la agravante por razones de género. Además, mientras que en la primera de ellas el sujeto pasivo podrá ser un varón, en el caso de la agravante por razones de género necesariamente habremos de encontrarnos ante una víctima perteneciente al sexo femenino.

En este sentido, REBOLLO VARGAS ${ }^{43}$, al tratar el fundamento de la agravante de discriminación por razón de sexo - y cuando todavía estaba siendo objeto de debate la incorporación de la de género al elenco regulado en el artículo 22.4 del $\mathrm{CP}$ - , afirma que el sujeto pasivo de la primera podrá ser hombre o mujer por el sólo hecho biológico de serlo: "si el art. 22.4 del Código Penal no contiene ninguna referencia al género no puede interpretarse que el sexo femenino sea la única condición personal que supone la agravación, de modo que no se aplicará la circunstancia agravante cuando el sujeto pretenda perpetrar unos determinados roles de género, sino cuando actúe motivado por el hecho de pretender causar un mal a su víctima por el sólo hecho de ser mujer u hombre".

Y prosigue el mismo autor remarcando la diferenciación entre los efectos derivados de la agravante de sexo y una potencial agravante de género: "en todo caso, quisiera reiterar que el art. 22.4 se refiere al sexo biológico de la víctima pero no a su género, otra cosa es que la agravante hiciera referencia expresa a la discriminación por razón de género, $[. .$.$] lo cual hubiera te-$ nido unos efectos diferentes a los que se desprenden de la actual agravante por razón de sexo" 44 .

42 DÍAZ LÓPEZ, El odio discriminatorio como agravante penal: sentido y alcance del artículo 22.4. ${ }^{a} \mathrm{CP}, 2013$, p. 300.

43 REBOLlo VARGAS, Revista General de Derecho Penal, $\mathrm{n}^{\circ}$ 23, 2015, p. 14.

44 En este último inciso, REBOLLO VARGAS referencia a DÍAZ LÓPEZ, El odio discriminatorio como agravante penal: sentido y alcance del artículo 22.4. ${ }^{a} C P, 2013$, pp. 303. 
En nuestra opinión, sin embargo, la agravante por razón de sexo se refiere fundamentalmente a las mujeres como colectivo discriminado. Estamos de acuerdo con MAQUEDA ABREU cuando afirma que la agravante del artículo $22.4^{\circ}$ selecciona a los grupos por su posición de subordinación, por lo que considerar que los hombres, como colectivo, puedan estar dentro de las potenciales víctimas de esta agravante no tiene razón de ser dado que se trata de un grupo de poder ${ }^{45}$. En efecto, sería como plantear que la agravante por razón de pertenencia a una nación fuera aplicable a supuestos en los que las víctimas fueran de nacionalidad española.

En el mismo sentido se ha manifestado recientemente RUEDA MARTÍN, quien, en primer lugar, rechaza que para la apreciación de discriminación por razón de sexo sea necesaria la motivación misógina, puesto que ello implica una limitación innecesaria, además de las dificultades probatorias que dicha exigencia trae consigo ${ }^{46}$. Además, esta autora añade que tanto la agravante por razón de sexo como la agravante por razón de género tienen elementos configuradores comunes. Así, afirma que el origen de la discriminación por razón del sexo femenino y por razón de género se relaciona siempre con ciertos caracteres diferenciales de la víctima; en concreto, un rasgo de identidad biológico del que se han derivado unas determinadas consecuencias fundamentadas en motivos histórico-culturales, y que se manifiestan a través de prejuicios, costumbres, tradiciones y prácticas basadas en la idea de la inferioridad de la mujer. Asimismo, ambas discriminaciones implican un trato peyorativo contra la

45 MAQUeda ABREU, Cuadernos de Política Criminal, $\mathrm{n}^{\circ} 118,2016$, p. 8. Esta autora indica que, si se considera que el sexo como motivo discriminatorio incluye ya a las mujeres, "las razones de género" a las que alude la nueva agravante podrían referirse a otros grupos excluidos tales como los travestis, drug queen, etc. Resulta interesante esta reflexión, pero ella misma reconoce que no va a ser ésta la interpretación que se haga de la agravante por razones de género. ACALE SÁNCHEZ, La discriminación hacia la mujer por razón de género en el Código Penal, 2006, pp.411 y ss.

46 RUEDA MARTÍN, RECPC 21-04 (2019), p. 9. 
mujer, que crea o profundiza la situación de inferioridad al privarle de libertad para decidir por sí misma si no es dentro del rol sexual asignado en la sociedad. Añade RUEDA MARTÍN que la discriminación por razón del sexo femenino y por razón de género tiene un efecto sobre la propia dignidad humana, al negarle a la mujer su condición de ser humano igual que el hombre $y$, finalmente, en las agresiones por razón del sexo femenino y por razón de género debe apreciarse un contexto coercitivo de dominación y de abuso de poder por parte del sujeto activo, que ponga de relieve los componentes de temor y agravio que han de ser probados en cada caso particular, ya que conforman el espacio discriminatorio que requiere el artículo $22.4^{\circ}$ del Código Penal. Compartimos la conclusión de RUEDA MARTÍN cuando afirma que tanto la discriminación por razón del sexo femenino como la que se produce por motivos de género son coincidentes por lo que el reproche recae sobre el mismo objeto ${ }^{47}$.

Por otra parte, no podemos evitar preguntarnos en qué supuesto de hecho se producirá un contexto de dominación propio de la agravante por razones de género sin que tal discriminación lleve aparejada de forma implícita una discriminación por razones de sexo. Es precisamente al sexo femenino al que se le atribuyen determinados roles de subordinación. No son las razones biológicas las que provocan dichas situaciones. En este sentido, entendemos que sexo y género en este contexto de la agravante expresan lo mismo ${ }^{48}$. Como acertadamente expresa MAQUEDA ABREU, la explicación que nos ofrece la Exposición de Motivos del Código Penal consistente en que el género puede constituir "fundamento de acciones discriminatorias diferentes del que abarca la referencia al sexo" resulta excesivamente pobre al no poder considerarse sexo y género como categorías estanco, simplemente teóricas, alejadas de una realidad fáctica capaz de fundamentar juicios de discriminación separados en función de si

47 RUEDA MARTÍN, RECPC 21-04 (2019), pp.25 y ss.

48 LARRAURI PIJOAN, Criminología crítica y violencia de género, 2007, pp. 127 y ss.; MAQUEDA ABREU, Cuadernos de Política Criminal, $\mathrm{n}^{\circ}$ 118, 2016, p. 8. 
nos encontramos ante una agravante $u$ otra. Coincidimos con la autora cuando expone las amplias dificultades a la hora de desligar las diferencias entre el machismo y la misoginia, resultando esta última una motivación compleja que, "aparte del odio, incluye significados como desprecio o la subestimación de las mujeres que son también ingredientes comunes al machismo" ${ }^{\text {"49 }}$.

Lo anterior nos lleva a concluir que, cuando la víctima sea mujer, la agravante de sexo perderá ampliamente su aplicación en favor de la de género. Y que probablemente hubiera sido suficiente la agravante por razón de sexo para abarcar estos supuestos. Sin embargo, como se ha puesto de manifiesto, los tribunales y algunos autores sí que otorgan a la agravante por razones de género un campo propio y diferenciado de la agravante por razón de sexo. Además de que se advierte cuando, se hace un recorrido jurisprudencial, que la agravante por razón de sexo ha tenido una aplicación prácticamente nula, por lo que esta nueva agravante puede servir como llamada de atención y tener cierto carácter pedagógico ${ }^{50}$.

Por tanto, consideramos acertada la incorporación de la agravante por razones de género por dos motivos. Si se considera, como defendemos nosotras, que los supuestos discriminatorios de género podrían haber sido incluidos en la agravante por razón de sexo, entonces la introducción expresa de la nueva agravante en nuestra normativa penal servirá para que definitivamente se aplique, puesto que la agravante por razón de sexo no era objeto de aplicación en la práctica. Por el contrario, si se considera que la agravante por razón de sexo no incluía los supuestos de discriminación por razones de género, la introducción de esta agravante es aún más acertada. En ningún caso, por tanto, estamos ante un Derecho Penal simbólico.

49 MAQUEDA ABREU, en SILVA/QUERALT/CORCOY/CASTIÑEIRA (coords.) Estudios de Derecho Penal: homenaje al profesor Santiago Mir Puig, 2017, pp. 707 y ss.

50 MAQUEDA ABREU Cuadernos de Política Criminal, nº 118, 2016, p. 13. 


\section{Aplicailidad de la agravante de discriminación por razo- nes de género}

Por lo indicado en el apartado anterior, debemos valorar positivamente la inclusión de la nueva agravante de género en nuestro Código Penal pues, sin perjuicio de que efectivamente la misma responde a la necesidad de dar cumplimiento a ciertos compromisos internacionales en esta materia, no es menos cierto que la agravante que nos ocupa puede tener $-\mathrm{y}$, de hecho, así se viene corroborando por los Tribunales ${ }^{51}$ — una aplicación práctica en aquellos supuestos de violencia de género que no posean figuras específicas tipificadas en el Código Penal — véase, a este respecto, por ejemplo, la violencia doméstica habitual, el asesinato o el homicidio-, permitiendo ampliar así el ámbito del Derecho penal sexuado ${ }^{52}$.

Resulta asimismo interesante la visión de ACALE SÁNCHEZ $^{53}$ cuando afirmaba — con anterioridad a la introducción de la agravante en nuestro Código Penal - que "una agravante genérica de discriminación por razón de género permitiría a los jueces valorar caso a caso el componente sexista de las conductas violentas de los hombres sobre las mujeres, evitando las presunciones injustificadas sobre la gravedad de la culpabilidad del autor o la inferioridad de la mujer que son consecuencias inevitables de las figuras género específicas".

51 Sentencia de la Audiencia Provincial de Asturias, no 517/2017, de 4 de diciembre, que aplica la agravante de desprecio de género y condena al autor como responsable de un delito de amenazas y de homicidio intentado. Sentencias de la Audiencia Provincial de Vizcaya, $n^{0}$ 34/2018, de 26 de abril, y de la Audiencia Provincial de Badajoz, $n^{\circ}$ 5/2018, de 5 de febrero, ambas condenando al autor como responsable de un delito de asesinato, concurriendo igualmente la agravante de género. Sentencia de la Audiencia Provincial de Cuenca, $n^{\circ} 4 / 2018$, de 6 de febrero, condenando al autor como responsable de un delito de agresión sexual, constitutivo de violación, concurriendo asimismo la agravante de género.

52 LAURENZO COPELLO, Estudios Penales y Criminológicos, Vol. XXXV, 2015, pp. 822-823.

53 ACALE SÁNCHEZ, La discriminación hacia la mujer por razón de género en el Código Penal, 2006, pp. 408-411. 
La aplicación indiscriminada de la agravante de género podría traer como consecuencia la vulneración del principio de inherencia contenido en el precepto $67 \mathrm{CP}$ - y, paralelamente al anterior, la del también principio non bis in idem-, al sancionar doblemente la misma conducta ${ }^{54}$. Por ello, se deberá excluir su aplicación en determinados casos.

Así, en primer lugar, la nueva agravante no podrá aplicarse en todas aquellas figuras a las que la Ley Orgánica 1/2004 ya otorgó una agravación por razones de género cuando la víctima fuere o hubiere sido esposa, o mujer que estuviere o hubiere estado ligada al autor por una análoga relación de afectividad, aun sin convivencia; esto es, los subtipos agravados de lesiones del artículo $148.4 \mathrm{CP}$, los malos tratos no habituales del artículo 153.1 CP, las amenazas leves del artículo $171.4 \mathrm{CP}$ y las coacciones leves del artículo 172.2 CP.

Por otra parte, como afirma PERAMATO MARTÍN ${ }^{55}$, la agravante de género no será tampoco aplicable en aquellos casos en los que las conductas enjuiciadas sean subsumibles en los tipos penales en los que ya está recogida, aún de forma implícita, la discriminación, la desigualdad o la relación de poder del hombre sobre la mujer. Nos referimos, por ejemplo, al delito de mutilación genital.

La agravante podrá, no obstante, aplicarse a aquellos supuestos de violencia contra la mujer que poseen mayor entidad y que carecen de figuras específicas tipificadas en el Código Penal: el homicidio del $138 \mathrm{CP}$, el asesinato del $139 \mathrm{CP}$, la propia violencia doméstica habitual del $173.2 \mathrm{CP}$, los delitos contra la libertad e indemnidad sexuales del $178 \mathrm{CP}$ y siguientes, etc ${ }^{56}$.

54 Al respecto, DÍAZ LÓPEZ, El odio discriminatorio como agravante penal: sentido y alcance del artículo 22.4. ${ }^{a} C P, 2013$, p. 316, nota a pie de página $\mathrm{n}^{\mathrm{o}} 120$, donde hace referencia la Sentencia del Tribunal Supremo $\mathrm{n}^{\mathrm{o}}$ $51 / 2008$, de 6 de febrero.

55 PERAMATO MARTÍN, Jueces para la Democracia $\mathrm{n}^{\circ}$ 2, 2016, p. 9; GARCÍA SEDANO, La Ley Penal n 131, marzo-abril 2018, p. 3.

56 LAURENZO COPELLO, Estudios Penales y Criminológicos, Vol. XXXV, 2015, pp. 822-823; RUEDA MARTÍN, RECPC 21-04 (2019), p. 23. 
Una de las cuestiones más interesantes que se plantea en torno a este punto es si la circunstancia agravante podrá aplicarse únicamente a las mujeres que sean o hayan sido pareja del agresor, esto es, de forma paralela a lo que establece la LO $1 / 2004$, o si, por el contrario, no es necesario apreciar esta relación de afectividad y puede aplicarse a cualquier delito que se cometa contra una mujer en el que se constate un contexto objetivo de dominio.

En este sentido, el Tribunal Supremo en su Sentencia ${ }^{\circ}$ 420/2018, de 25 de septiembre, afirma que "con la introducción de la agravante relativa a cometer el delito por una discriminación basada en razones de género, se amplía esta protección con carácter general, de modo que la agravación de la pena no solamente es procedente en los casos expresamente contemplados en las descripciones típicas de la parte especial, en los que las razones de la agravación ya vienen contempladas en el tipo, sino en todos aquellos otros casos en los que la discriminación por esas razones, basadas en la intención de dominación del hombre sobre la mujer, que dentro de las relaciones de pareja es considerada por el autor como un ser inferior, vulnerando, por lo tanto, su derecho a la igualdad, aparezcan como motivos o móviles de la conducta". Es decir, en su primera Sentencia aplicando la agravante de género el Tribunal Supremo indica que el ámbito de sujetos se circunscribe a las relaciones de pareja.

Sin embargo, ya en su Sentencia $n^{\circ} 565 / 2018$, de 19 de noviembre, rectifica la anterior al poner de manifiesto una ampliación del ámbito de aplicación de la circunstancia agravante de discriminación por razones de género respecto de los supuestos calificados como violencia de género conforme al artículo 1 de la Ley Orgánica 1/2004, ya que considera que no se circunscribe sólo a la violencia ejercida por un hombre sobre su pareja o ex pareja mujer. En particular, el Tribunal Supremo expone que esta agravante no concreta su ámbito de aplicación de forma exclusiva a las relaciones de pareja o ex pareja, sino a "cualquier ataque a la mujer con efectos de dominación, por el hecho de 
ser mujer". Concluye esta Sentencia que "el fundamento de la agravante se ubica en la mayor reprochabilidad que supone que el autor cometa los hechos contra una mujer por el mero hecho de serlo [...]. Porque el ilícito penal que se cometa se asienta sobre la consideración de un trato desigual, precisamente por su diferente sexo $[\ldots]$, pero sin el aditamento de que sea pareja del agresor, o su ex pareja, sino esencial y únicamente por ser mujer".

Este cambio de criterio del Tribunal Supremo es criticado por RUEDA MARTÍN, quien afirma que "desde mi punto de vista, la posición jurisprudencial sostenida en las SsTS n. ${ }^{\circ}$ 565/2018, de 19 de noviembre, y n. ${ }^{\circ}$ 99/2019, de 26 febrero, choca frontalmente con la vinculación material existente entre la discriminación por razones de género y la violencia de género, reconocida por el propio legislador en el Preámbulo de la Ley Orgánica $1 / 2015$, de 30 de marzo, y por nuestra jurisprudencia. Con arreglo a una interpretación teleológico-sistemática es obligado circunscribir el ámbito de aplicación de la circunstancia agravante de discriminación por razones de género a la violencia ejercida por un hombre sobre su pareja o ex pareja mujer, tal y como se dispone en el artículo 1 de la Ley Orgánica 1/2004"57.

No podemos compartir la crítica de RUEDA MARTÍN. En nuestra opinión, el hecho de que la LO 1/2004 circunscriba su ámbito de aplicación a la violencia sobre la pareja o ex pareja no obliga, desde un punto de vista sistemático, a que ello tenga que aplicarse a una circunstancia agravante integrada en la parte general del Código Penal ${ }^{58}$, máxime teniendo en cuenta que la LO 1/2004 se aleja en su definición de violencia de género de otras normativas, especialmente del Convenio de Estambul.

Desde un punto de vista material, obsérvese que, de no existir este cambio de criterio por el Tribunal Supremo, la agra-

57 RUEDA MARTÍN, RECPC 21-04 (20199, p. 23.

58 Téngase en cuenta asimismo que, como hemos expuesto en líneas anteriores, precisamente esta limitación de la LO 1/2004 la consideramos criticable por circunscribir su ámbito a las relaciones de pareja y ex pareja, alejándose de la normativa internacional. 
vante de género no podría aplicarse en todos aquellos casos en los que la agresión contra la mujer se produce fuera del ámbito de las relaciones afectivas de pareja - una mujer agredida por un hombre desconocido, o los casos de explotación sexual femenina, lapidaciones a mujeres, matrimonios forzados, etc., que constituyen, sin lugar a dudas, manifestaciones claras de violencia de género al afectar de forma desproporcionada a las mujeres $^{59}$-, así como en aquellos supuestos en los que las víctimas fueran otras mujeres del contexto familiar (por ejemplo, hijas o abuelas) para las que el Código Penal no contempla una protección reforzada - más allá de su inclusión como sujetos pasivos dentro del delito de violencia doméstica-, salvo que se pruebe su especial vulnerabilidad y la convivencia con el autor.

Conviene indicar asimismo que, según nuestro criterio, nada obstaría a la apreciación de la agravante de género en los denominados delitos leves. A estos efectos, el precepto $66.2 \mathrm{CP}$ establece que en esta modalidad de delitos, los jueces o tribunales aplicarán las penas a su prudente arbitrio, sin sujetarse a las reglas prescritas en el apartado anterior. Por lo anterior, consideramos que nada impide que pueda tenerse en consideración la agravante de género si se produce la concurrencia de los elementos ya comentados que rigen la misma.

Para concluir, nos planteamos si tiene sentido, ante la inclusión de la agravante, mantener en nuestra legislación penal estas figuras de género específicas. Siendo puristas podríamos conceder una respuesta negativa a esta cuestión pues, efectivamente, parece innecesario mantener vigente un conjunto de figuras agravadas si la agravante, dado su carácter genérico, podría ser aplicada en todos esos supuestos de hecho. Máxime si tomamos en consideración que para la aplicación de estos tipos específicos los Tribunales han exigido un contexto objetivo de

59 El artículo 3 d) del Convenio de Estambul establece que "por violencia contra la mujer por razones de género se entenderá toda violencia contra una mujer porque es una mujer o que afecte a las mujeres de manera desproporcionada". 
dominación o los han aplicado de forma automática, mientras que - sin perjuicio de las escasas sentencias habidas hasta el momento- el Tribunal Supremo ha tendido en la mayoría de sus resoluciones aplicando la agravante a la necesidad de exigir un elemento subjetivo de dominación. Es evidente, por tanto, que se observa una clara discordancia entre lo exigido para aplicar los tipos reforzados y lo que parece que se exigirá para la aplicación de la agravante.

Ahora bien, tampoco podemos evitar preguntarnos qué sucedería en la práctica si procediéramos a la eliminación de estas figuras de género específicas. Probablemente numerosos casos de violencia de género ya no serían enjuiciados como tales pues dependeríamos exclusivamente de la capacidad de las partes para probar la concurrencia de una agravante que posee como uno de sus elementos básicos el carácter intencional del autor, lo cual conlleva necesariamente esa dificultad probatoria a la que ampliamente ya hemos hecho referencia en líneas precedentes. Amén de lo anterior, la supresión parcial de ciertos preceptos introducidos por una Ley específica creada para combatir la Violencia contra la Mujer transmitiría a nivel social una sensación de impunidad respecto al campo que nos ocupa que consideramos perfectamente evitable, máxime cuando no es incompatible la convivencia de los artículos que hemos tratado con la inclusión de la agravante. En todo caso, somos plenamente conscientes de que se trata de un tema que generará abundante debate entre la doctrina.

\section{CONCLUSIONES}

A modo de cierre del presente trabajo, debemos concluir que se antoja fundamental preguntarnos por las razones por las que se incluye la presente agravante. Como hemos dejado expuesto, la introducción de la presente agravante no responde solamente al deber de dar respuesta a ciertos compromisos internacionales, ni cumple una mera función simbólica en nuestro 
derecho, sino que posee una aplicación práctica que ya se ha visto reflejada a través de diferentes sentencias.

A la hora de analizar el fundamento de la agravante habremos de tener presente, tanto el resultado objetivamente discriminatorio que la conducta en sí genera sobre la víctima, como, en su caso, ese efecto comunicativo amenazante que se pueda producir sobre el colectivo al que ésta pertenece. Será el contexto objetivo de dominación, el cual vendrá marcado por el comportamiento del autor, más allá de por sus motivaciones o intenciones concretas en el momento de la comisión del delito, el que determine la aplicación de la agravante. La sustitución del componente intencional exigido por los tribunales por un elemento de carácter objetivo nos permitirá alejarnos de las amplias dificultades probatorias que conlleva todo fundamento subjetivo, amén de valorar la conducta delictiva simplemente por la gravedad del injusto y no por la gravedad de la culpabilidad que atribuyamos al autor en función de su motivación. En todo caso, resulta ampliamente positiva la ya comentada Sentencia del Tribunal Supremo no 99/2019 pues nos permite empezar a vislumbrar un cambio jurisprudencial en relación a la exigencia del elemento motivacional.

Respecto a la diferencia entre la agravante por razón de sexo y la agravante por razón de género consideramos que en este contexto sexo y género expresan lo mismo. Entendemos, no obstante, que la nueva agravante tendrá un marcado efecto pedagógico como consecuencia de la escasa aplicación que venía sufriendo la agravante de sexo.

En cuanto a la aplicabilidad de la agravante, habremos de ser cautelosos con el principio de inherencia - en estrecha relación con el principio non bis in idem-, de modo que la misma no podrá aplicarse en aquellos preceptos a los que la Ley Orgánica 1/2004 ya otorgó una agravación por razones de género cuando la víctima fuere o hubiere sido esposa, o mujer que estuviere o hubiere estado ligada al autor por una análoga relación de afectividad, aun sin convivencia (148.4 CP, 153.1 CP, 171.4 CP y 172.2 CP). Precisamente, respecto a estas figuras de género 
específicas, cabrá preguntarse si las mismas podrían ser objeto de supresión ante la inclusión de la agravante. Sin perjuicio de que la respuesta no será pacífica entre la doctrina, en todo caso, consideramos relevante valorar las consecuencias que se derivarían en el supuesto de responder afirmativamente a la cuestión, máxime cuando los tribunales exigen un claro elemento subjetivo - con sus inherentes dificultades probatorias - para poder aplicar esta circunstancia modificativa.

Por el contrario, no observamos ningún inconveniente en que la agravante sea de aplicabilidad a todos aquellos supuestos que no poseen figuras específicas de violencia de género tipificadas en el Código Penal siempre que, naturalmente, concurran los presupuestos que han de regir la aplicación de la agravante - a título meramente enunciativo, nos permitiremos citar el homicidio contenido en el $138 \mathrm{CP}$, el asesinato del $139 \mathrm{CP}$, la propia violencia doméstica habitual del $173.2 \mathrm{CP}$, los delitos contra la libertad e indemnidad sexuales del $178 \mathrm{CP}$ y siguientes, etc.- .

Por último, no encontramos impedimento a que la agravante sea de aplicación a los delitos denominados leves.

\section{BIBLIOGRAFÍA}

ACALE SÁNCHEZ, M., La discriminación hacia la mujer por razón de género en el Código Penal, Madrid, 2006.

AGUILAR CÁRCELES, M.M. "Circunstancias agravantes genéricas", en MORILLAS CUEVA, L. (dir.), Estudios sobre el Código Penal reformado, Madrid, 2015, pp. 58-63.

ALONSO ÁLAMO, M. "La circunstancia agravante de discriminación”, en DÍEZ RIPOLLÉS, J.L. (coord.), La Ciencia del Derecho penal ante el nuevo siglo: libro homenaje al Profesor Doctor Don José Cerezo Mir, Madrid, 2002, pp. 533-542.

BERGALLI, R./BODELÓN GONZÁLEZ, E., "La cuestión de las mujeres y el derecho penal simbólico" en Anuario de Filosofia del Derecho IX. 1992, pp. 43-74. 
BORJA JIMENEZ, E. "La circunstancia agravante de discriminación” en GONZÁLEZ CUSSAC, J.L. (dir.), Comentarios a la Reforma del Código Penal 2015, Valencia, 2015, pp. 119-123.

DÍAZ LÓPEZ, J.A., El odio discriminatorio como agravante penal: sentido y alcance del artículo 22.4. ${ }^{a} C P$, Madrid, 2013.

DOPICO GÓMEZ-ALLER, J., "Delitos cometidos por motivos discriminatorios. Una aproximación desde los criterios de legitimación de la pena" en $A D P C P$, vol. LVII, 2004, pp. 143-176.

GARCÍA SEDANO, T. "La circunstancia agravante de género" en LA LEY Penal no 131, marzo-abril 2018, pp. 1-7.

JAKOBS, G., "Criminalización en el estadio previo a la lesión de un bien jurídico" en Estudios de Derecho Penal, Madrid, 1997, pp. 293-324.

LANDA GOROSTIZA, J., La política criminal contra la xenofobia y las tendencias expansionistas del derecho penal, Granada, 2001.

LANDA GOROSTIZA, J., "Recensión a Juan Alberto Díaz López, El odio discriminatorio como agravante penal. Sentido y alcance del artículo $22.4^{\mathrm{a}} \mathrm{CP}$ ” en InDret, $3 / 2014$, pp. 1-46.

LANDA GOROSTIZA, J., Los delitos de odio, Valencia, 2018.

LARRAURI PIJOAN, E., Criminología crítica y violencia de género, Madrid, 2007.

LAURENZO COPELLO, P., "La discriminación en el Código penal de 1995", en Estudios Penales y Criminológicos, vol. XIX, 1996, pp. 219-288.

LAURENZO COPELLO, P. "La violencia de género en el Derecho penal: un ejemplo de paternalismo punitivo", en LAURENZO/MAQUEDA/RUBIO (coords.), Género, Violencia y Derecho, Valencia, 2008, pp. 329-362.

LAURENZO COPELLO, P. “¿Hacen falta figuras de género específicas para proteger mejor a las mujeres?", en Estudios Penales y Criminológicos, vol. XXXV, 2015, pp. 783-830. 
MAQUEDA ABREU, M.L., "La violencia de género. Entre el concepto jurídico y la realidad social", en Revista Electrónica de Ciencia penal y Criminología, $\mathrm{n}^{\mathrm{o}}$ 8, 2006, pp. 1-13.

MAQUEDA ABREU, M.L., "El hábito de legislar sin ton ni son. Una lectura feminista de la reforma penal de 2015.", en Cuadernos de política Criminal, $\mathrm{n}^{\circ} 118,2016$, pp. 5-42.

MAQUEDA ABREU, M.L., “Necesitan un móvil discriminatorio las agravantes de sexo/género del art. 22.4 CP?", en SILVA/QUERALT/CORCOY/CASTIÑEIRA (coords. Estudios de Derecho Penal: homenaje al profesor Santiago Mir Puig, Buenos Aires, 2017, pp. 703-714.

MIR PUIG, S., Derecho Penal. Parte General, $10^{\mathrm{a}}$ ed., Madrid, 2016.

MUÑOZ COMPANY, M.J., "Violencia de género y necesidad o no de elemento subjetivo específico de dominación. Jurisprudencia y legislación vigente." en Diario La Ley, $\mathrm{n}^{\circ} 8606,2015$.

PERAMATO MARTÍN, T. "Modificaciones en el Código penal, Ley Orgánica 1/2015, de 30 de marzo, en materia de Violencia de Género" en Boletín de la Comisión de violencia de género Jueces para la Democracia $\mathrm{n}^{\circ}$ 2, 2016, pp. 7-11.

REBOLLO VARGAS, R., "La agravante de discriminación por razón de sexo y su fundamento (art. 22.4 del Código Penal)", en Revista General de Derecho Penal, n 23, 2015, pp. 1-28.

RUEDA MARTIN, M.A., "Cometer un delito por discriminación referente al sexo de la víctima y/o por razones de género como circunstancia agravante genérica", en Revista Electrónica de Ciencias Penales y Criminología, 21-04 (2019), pp. 1-37. 